\title{
Is Telepathy Allowed or Is Controled?
}

\author{
Viviana Siddhi* \\ Slovenian-born artist, NGO Mandala Transformation, USA
}

*Corresponding author: Viviana Siddhi, Slovenian-born artist with American citizenship, NGO Mandala Transformation, Inc., California, USA.

Received Date: May 29, 2019

Published Date: June 11, 2019

\section{Introduction}

Telepathy is not just a myth and science fiction. Science has proven that to some extent is possible.

The history of telepathy goes back to the ancient Egyptians and Greeks. Egyptians believed that a spirit would send messages from one person to another in dreams. The Greeks also believed dreams were a way to send messages. Ancient knowledge as dreams, telepathy, etc. was preserved by many indigenous people.

The term telepathy was first used in 1882 by psychologist F.W. Myers who helped start the Society of Psychical Research. "There is no scientific proof that human telepathy exists. Telepathy means direct communication from one mind to another. It refers to the supposed ability to perceive the thoughts of others without the use of recognized senses." In another words, telepathic communication is the ability to transmit information from one mind to another and telepathic perception is the ability to receive information from another mind.

When telepathy influences another person's thoughts or beliefs, it is called mind control. Within USA is quite developed. Unfortunately, a lot of people are applying mind control at night when it's time for us to sleep. Mind control involves influence and can include outside props or strategies to achieve its goal. Since, it involves influences of other people (known and unknown) it can be very beneficial or crucifixion. It can be helpful for us to make life changes and it can also create destructions for a lifetime. All depends on the person who is imposing his will (power) into somebody else's mind. This kind of knowledge should possess only people with pure hearts; however, reality is different. Indigenous people are taught sacred knowledge in order to keep it alive from generation to generation.

When one starts to naturally experience the awakening of telepathic powers, he/she feels more energized. One will start to refrain from negativity and thus, your friends will either be happy or you or they will fall away. Those who are used to talking about negative things will fall away first, since they will lose interest in your company. My experience is that many are trying to prevent that one person will have more telepathic powers then others. Negative people are not pure in their hearts, minds, souls and their bodies. They are looking only how to benefit, or they want to control somebody else's life and decisions in order to satisfy their own or another person's goals. Many are paid for such kind of "jobs". Such kind of destructions are creating bad karmas for the person who is imposing their will into somebody else's mind and for receiver of that influence. Such kind of situations are an open window for major psychic attacks in order to block spiritual progress of another person. Instead to focus on our own challenges and try to resolve them one by one, we are exposed to additional suffering just because of others who are not interested to resolve their own problems. It is easier to create destructions. Such kind of people do not want to dig deep inside their own soul and see how they can improve their life and/or health. We are all here, on this planet earth to learn and not to judge. Nobody has the right to judge others because nobody knows somebody else's experiences and abilities to learn from them.

"Everyone occasionally suffers from depression, and some people are stricken with major depression, in which the sadness and hopelessness last more than two weeks and interfere with carrying on with life. In recent decades, more people have been diagnosed with depression, especially in younger cohorts, and the conventional wisdom is captured in the tag line of a recent public television documentary: "A silent epidemic is ravaging the nation and killing our kids." We have just seen that the nation is not suffering from an epidemic of unhappiness, loneliness, or suicide, so an epidemic of depression seems unlikely, and it turns out to be an illusion" [1].

Brian Clegg mentioned in his book Extra Sensory: "Not only is the flexibility Rhine describes dangerous, in that it can be easy to 
ascribe results to conditions that didn't actually apply; there is also the problem that is almost impossible to ignore any positive results coming out of the badly controlled trials" [2].

\section{Natural Way of Spiritual Growth Is Changing Our Perceptions}

Arguments that used to keep us up at night will start to have different meaning. All the things that we placed at utmost importance will lose their relevance. One will choose to put more importance on spiritual things. Everything we will see with new eyes. The third eye it awakens in the pineal gland. The universe starts to put new people in our path and new opportunities for better life. One will gain clarity about others and different situations. This, in turn will cause priority changes.

\section{Plant the Seedling of Devotion in The Mind}

Man should be the master of his behavior; he should not be led away by the impulse of the moment; he must be conscious always of what is good for him. He should so carry on his daily tasks that he does not make others suffer or suffer himself. That is the sign of intelligent living. You should not give way to fits of anger or grief or elation or despair. The confusion you exhibited now was the result of Thaamasik (dark and dull) and Raajasik (emotional) qualities. Be Saathwik, calm and unruffled and collected. The more you develop charity for all beings, contrition at your own faults, fear of wrong and fear of God - the more firmly established you are in Shaanthi (peace).

In this spiritual sphere of mental peace and inner joy, the responsibility for success or failure is entirely one's own. You have no right to shift it on to others. The fire will go out if the fuel is over; so, stop feeding it with fuel. Do not add fuel to the fire of the senses. Detach the mind from the temporary and attach it to the eternal. The negative Shakthi (power) and the positive Shakthi both together will give the light. Plant the seedling of Bhakthi (devotion), namely, the preliminary exercise of Naamasmarana (remembering the Lord's name), in the mind. That will grow into a tree with the branches of virtue, service, sacrifice, love, equanimity, fortitude and courage. You swallow food, but you are not aware how that food is transformed into energy, intelligence, emotion and health. In the same way, just swallow this food for the spirit, this Naamasmarana, and watch how it gets transmuted as virtue and the rest without your being aware of it" [3].

\section{What Is the Science Behind It?}

Recent studies have reported direct transmission of brain activity between two animals, between two humans and even between a human and an animal. These "brain-to-brain interfaces" allow for direct transmission of brain activity.

"Starting around 2013, several groups of researchers began experimenting with telepathy. These researchers worked in an area of science called neuroscience. Neuroscientists study the brain and how it works. In their experiments, the researchers had some positive results with a process known as synaptic transmission.
The brain is part of the nervous system. This system houses all the nerve cells in the body. Synapses are where nerve cells in the body meet. The synapses carry chemical and electrical signals throughout the brain and body. Normally, this is done without the person even thinking about it. For example, when a person moves their arm, the brain sends a message to the arm to move. That message is carried over the brain's synapses. The person doesn't think about moving their arm. It just happens because the brain sees that the arm needs to move and sends the message" [4].

Recent advances in brain-computer interfaces are turning the science fantasy of transmitting thoughts directly from one brain to another into reality.

"Mark Zuckerberg, the founder of Facebook, commented in 2015 that he believes the future of communication is in telepathy. He thinks technology will be the key to sending thoughts directly to other people. While it might sound like a distant dream, he may not be wrong." [5].

“The building that house Facebook's headquarters are on a large campus in California. The complex is visible from the main road, and there isn't much mystery about it. However, one mysterious part of it is a research lab called Building 8. Not much is known about what projects are being developed at the company. But Facebook has several scientists and technology experts working for them.

One new technology could involve reading people's minds. A neuroscientist works for the company. He is known for inventing a mind-operated prosthetic arm. Building 8 might be working on more mind-controlled technology, including computers. Job postings for positions in Building 8 seem to be looking for employees whose skills relate to telepathy and technology.

Only time will tell what's really going on there. But if Facebook is successful in implementing "brain-to-brain" communication, maybe they won't even have to tell the public what's going on - the public will just know" [6].

I experienced by myself very destructive energies at the Facebook internet pages since I had a lot of friends involved at my personal pages. I am assuming that this feeling was part of Facebook's experiments. If one is very active and popular at personal Facebook page, it allows others to use that page without communicating with the "owner of particular page" for various goals including business and political conversations. If this is the case it will be for the "owner of the personal page" hard to close the Facebook account especially if one does not have access to it, anymore. Japanese scientists believe that we can create earth changes with computers (earthquakes...). This happens when there are opposite energies involved with a higher power. Unfortunately, some people (unconsciously and/or consciously) are creating car accidents by using opposite energies/opinions of majority people. All mentioned above it leads me to conclusion that most car accidents are energy work. People who are sending negative energies can badly influence others. Such kind of situations has a significant impact on our health, life decisions, accidents, etc. 


\section{Negative People More Likely to Be Involved in Car Accidents, Study Finds}

Being a pessimist could make you more prone to being involved in car accidents, according to a new study. Researchers from the Chinese Academy of Science's Institute of Psychology in Beijing have studied the character traits of drivers to discover whether someone's outlook on life could influence their likelihood of crashing.

The study, published in the journal Plus One, analyzed 38 drivers with at least three years' driving experience. Both groups were surveyed on their driving habits, including whether or not they wore a seatbelt or would drive through a red light. Each participant was then asked to identify weather a series of photographs had a red or blue border - the images in the photographs were chosen to incite negative, positive or neutral emotions in the participants. The study revealed drivers classed as "dangerous" took longer to identify the color of the border when shown a negative image. This, according to the researchers, indicated a negativity bias the name given by psychologists to the human tendency to be more influenced by negative experiences. Negativity bias was not detected among drivers in the "safe" group, and there was no difference in their response time to photos. The emotional effect creates a "visual tunneling", hindering a person's ability to be fully lucid in the present and making it more difficult for a driver to think swiftly and clearly.

Previous researchers have not explored the relationship between emotional information processing and driving behavior, said the study's researchers led by Dr. Jing Chai. Drivers with strong negativity biases reported having been involved in more crashes compared with less-biased drivers.

Overall, anger increases someone's susceptibility of colliding on the road. But, understanding that a high number of accidents may be due to someone's attitude could help researchers delve further into understanding what causes human error on the road. Researchers concluded: "The influence of negativity bias provides a possible explanation for the effects of individual difference on dangerous driving and traffic crashes" (7).

It is proven that psychic attacks effects/influences our emotional state of mind.

"When neuroscientists wanted to create telepathy between two human beings, they focused on synapses and how they send messages. They attached special electrodes to a helmet. The helmet was worn by a person in the experiment. The electrodes could read the brain activity of the person wearing the helmet. In one test, the person was giving a greeting. In another test, the person was making a hand movement. The electrodes read the activity going on in the brain of the person performing the activity. That activity was then translated into binary code and sent to another person far away. In one case, the other person was 5,000 miles away! On the receiving end, the coded messages were decoded. Then the decoded messages were fed to the receiving person's brain using a process known as transcranial magnetic stimulation (TMS).

The technology didn't work perfectly, but it worked well enough for researchers to believe they were closer to creating telepathy. According to researchers, this type of development could be useful for soldiers on the battlefield who need to receive instructions from a commanding officer or from another soldier" [8].

Soldiers at Vietnam war using telepathy. Sacred knowledge was one of the most important ways for survival and returns back home; however, many still suffers because of war cruelty. Government is using indigenous people for wars because they inherent sacred knowledge of telepathy and much more.

\section{Reading the Brainwaves}

"Brain-to-brain interface is made possible because of the way brain cells communicate with each other. Cell-to-cell communication occurs via a process known as synaptic transmission, where chemical signals are passed between cells resulting in electrical spikes in the receiving cell. Synaptic transmission forms the basis of all brain activity, including motor control, memory, perception and emotion because cells are connected in a network, brain activity produces a synchronized pulse of electrical activity, which is called a "brain wave".

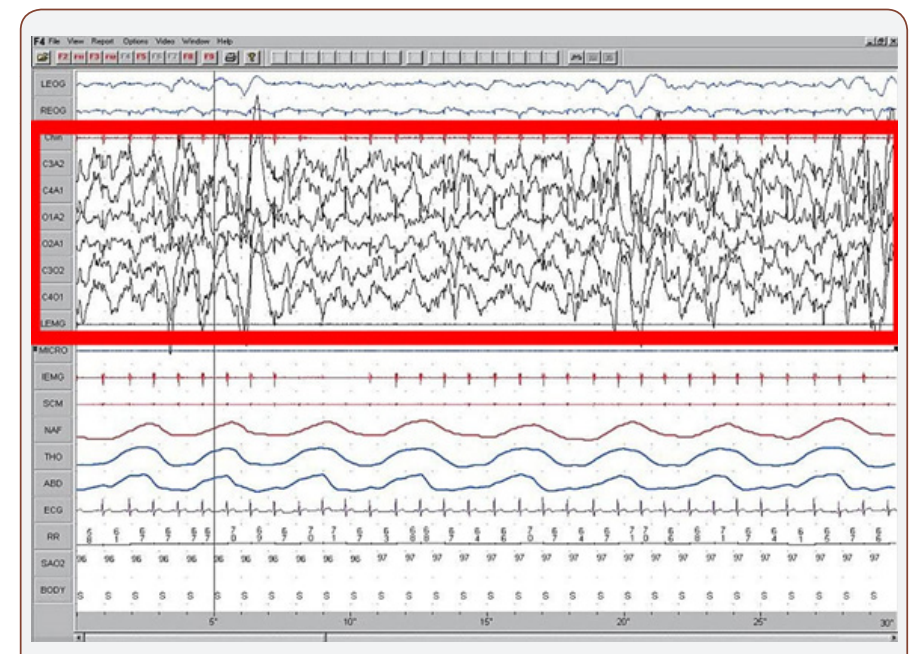

Figure 1: An example of brainwaves that appear during one of the stages of sleep.

Brainwaves are detected using a technique known as electroencephalography (EEG), where a swimming-cap like device is worn over the scalp and electrical activity detected via electrodes. The pattern of activity is then recorded and interpreted using computer software. This kind of brain-machine interface forms the basis of neural prosthesis technology and is used to restore brain function. This may sound far-fetched, but neural prostheses are actually commonplace, just think of the Cochlear implant!" [9].

\section{Meditation and Yoga Breathing}

"From the earliest times, the need to quiet our emotions has been seen as an essential step on the road to spiritual development. To access high wisdom and guidance, our emotional bodies must be still and calm. In most spiritual disciplines, the emphasis is put 
on quieting the mental body. When we refine our bodies, it's best to work from the bottom up. Quieting the mind becomes easier when our emotional bodies are calm. As Jacob Needleman points out, Socrates and Plato both wrote of a universal intelligence that could awaken in man only when our emotions are mastered" [10].

Refining the emotional body is one of the biggest challenges. Emotional turmoil will block our reception of information from the subtle planes. This is the reason why we got caught in illusions during meditation and we are receiving false information that can be against us. It is very important to reach "empty space" before we believe in any information that are coming into our mind. This state of mind is very easy to achieve via active meditation. For over 30 years I was teaching mandala workshops and realized that active meditation combines three components. It can be any kind of slowmotion action that combines three components and it brings us into "empty space" where everything is possible. This is the state of mind where is no time and therefore it allows us to be in now. It by itself brings best solutions for our better daily life. So called "empty space" is Samadhi.

When we rest at this stage we do not age anymore. There are different stages of Samadhi. Some can reach this state of mind for a second, some for few minutes, some for hours, days, etc. It is available to everybody, anytime, everywhere.

"The meditators in our study had an average of twenty-one years of a daily active practice; the nonmeditators had no active meditation practice, and most of them had never meditated at all. We predicted that the brain would show differences in electrical activity before unpredictable audio tones versus light flashes (because the brain processes these stimuli in different regions, thus creating different future brain states that might "ripple" backward in time).

The results of the experiment indicated that the nonmeditators showed no significant differences in brain activity before they received audio tones versus light flashes. But in the meditator' group, five of the thirty-two EEG electrodes showed statistically significant differences before receiving audio versus light stimuli (each electrode with odds against chance of 20 to 1) one second before the stimuli [11].

“This means that the meditators' brains behaved dramatically differently just before the audio tone, as compared to the nonmeditators' brain" [12].
Yoga breathing techniques are very useful for emotional, mind and body clearing; however, they have to be performed, daily.

"In this spiritual sphere of mental peace and inner joy, the responsibility for success or failure is entirely one's own. You have no right to shift it on to others. The fire will go our if the fuel is over; so, stop feeding it with fuel. Do not add fuel to the fire of the senses. Detach the mind from the temporary and attach it to the eternal. The negative Shakthi (power) and the positive Shakthi both together will give the light" [13].

\section{Acknowledgement}

None.

\section{Conflict of Interest}

No conflict of interest.

\section{References}

1. Steven Pinker (2018) Enlightenment Now, New York, USA, Penguin Random House LLC, pp. 280.

2. Brian Clegg (2013) Extra Sensory, New York, USA, St.Martin's Press, pp. 161.

3. Sri Satya Sai Baba (1961), Discourse Udumalpet Believe in Yourself, Bengaluru, India, Sri Satya Sai Baba Books and Publications Trust.

4. Cathleen Small (2019) The Science of Mind Control and Telepathy, New York, USA, Cavendish Square Publishing LLC., pp. 16.

5. Cathleen Small (2019) The Science of Mind Control and Telepathy, New York, USA, Cavendish Square Publishing LLC., pp. 35.

6. Cathleen Small (2019) The Science of Mind Control and Telepathy, New York, USA, Cavendish Square Publishing LLC., pp. 38.

7. Alexandra Sims (2016) The Independent News/Science, London, Independence Digital News and Media.

8. Cathleen Small (2019) The Science of Mind Control and Telepathy, New York, USA, Cavendish Square Publishing LLC., pp. 17.

9. Kristyn Bates (2015) Brain-to-brain Interfaces: the science of telepathy, USA, The Conversation, Academic Rigor, Journalistic flair.

10. Coleen Mauro (2015) Spiritual Telepathy, Quest Books, Wheaton, IL, pp: 92.

11. Dean Radin PhD, Supernormal Science, Yoga, and The Evidence for Extraordinary Psychic Abilities, New York, USA, Deepak Chopra Books, pp. 159.

12. Dean Radin PhD, Supernormal Science, Yoga, and The Evidence for Extraordinary Psychic Abilities, New York, USA, Deepak Chopra Books, pp. 160.

13. Sri Satya Sai Baba (1961) Discourse Udumalpet Believe in Yourself, Bengaluru, India, Sri Satya Sai Baba Books and Publications Trust. 